\title{
Editorial Assessing Antarctic Science
}

$\mathrm{T}$ The joint inspection team from Australia, Peru and the United Kingdom, reporting at XXVIII ATCM, concluded that science quality and output was very variable and proposed that SCAR should be asked to undertake an in situ assessment of all Antarctic research. SCAR declined but the questions about science remain to be answered. How?

Recognizing the problems with publication metrics let us then consider a paper by Prabir Dastidar and Olle Persoon called "Mapping the global structure of Antarctic research vis-à-vis Antarctic Treaty System" (Current Science, 89, 1552-1554, [2005]). Using 10,287 papers from 934 journals over a period of 24 years (1980-2003) they provide some interesting statistics on the origin of papers (using the first author address), citations given and received, and use multidimensional scaling to produce an analysis of collaborations between the top 35 countries. This statistical approach is one way of assessing aspects of scientific contributions at a national level.

Some results are not unexpected. In terms of papers produced the USA is far in front with 3311 papers, followed by the UK (1738), Australia (1259) and Germany (1191). Interestingly Israel, Taiwan, and Ireland - none of them signatories to the Antarctic Treaty - make it into the top 35 countries. In terms of productivity some Acceding Parties like Canada, Austria, Greece, Hungary, Czech Republic, Denmark and Switzerland score quite well, especially when compared to Consultative Parties such as Ecuador, Uruguay and Peru who fail even to make it into the top 35 countries.

There has been a steady rise in multinational papers to about $30 \%$ of the total each year, a trend supportive of the Treaty objectives. The network analysis shows that the most "collaborative countries" are, in order, USA, UK, Germany, France, Australia and Italy and with many others only showing very low links. The present efforts by SCAR to include the fullest range of countries in major projects like CAML, ice coring and even subglacial lakes research thus appears absolutely necessary.

The citation analysis provides some unexpected results. Ordering by mean citations per paper shows Israel, Canada, Denmark and Norway all with four or more but, since the total number of papers for most of these countries is small, this result is potentially skewed. Ordering the next 10 countries by mean citations gives UK, New Zealand, Belgium, France, Sweden, USA, Australia, Switzerland, Germany, Argentina. But just who is citing who? Is it mainly incestuous within the Antarctic community?

So let us identify some limitations in this analysis. Using the Science Citation Index provides coverage of all of the major international journals but is not comprehensive. The Antarctic Bibliography contains many more listings than SCI, including non-refereed and national publications, with over 2000 additions per year in the 1990s and currently over 8000 publications per year. In addition extraction of papers was based on a title search using "Antarc*", which is biased against some subjects (e.g. atmospheric sciences and oceanography) and will probably miss relevant Earth System Science papers.

Undertaking this assessment again using the Antarctic Bibliography as the primary source would provide more comprehensive cover, whilst weighting paper production by years since a country became a Consultative Party could provide an "index of commitment". Expanding search terms to include Southern Ocean and analysis of the most highly cited articles could also be valuable.

Here we have a potentially valuable assessment tool to answer some of the questions raised. How critical is Antarctic science in determining how planet Earth works? Is this investment good value for money? What could we change to increase its significance? Who will be brave enough to use these tools to identify the most valuable ways forward?

DAVID W.H.WALTON 
https://doi.org/10.1017/S0954102007000375 Published online by Cambridge University Press 